\title{
IMPLEMENTAÇÃO E AVALIAÇÃO DO MONITORAMENTO DE ALGAS NOCIVAS E DE FICOTOXINAS EM UM CULLTIVO DE MOLUSCOS EM FLORIANÓPOLIS - SC.
}

THIAGO PEREIRA ALVES ${ }^{1}$; MATHIAS ALBERTO SCHRAMM; MÁRCIO DA SILVA TAMANAHA; LUÍS ANTÔNIO DE OLIVEIRA PROENÇA.

Universidade do Vale do Itajaí - Centro de Ciências Tecnológicas da Terra e do Mar, CTTMar, Rua Uruguai, 458, 88302-202, Itajaí, SC, Brasil Laboratório de Estudos sobre Algas Nocivas, Laboratório de Oceanografia Química

1oceano.thiago@gmail.com

\begin{abstract}
RESUMO
Florações de algas nocivas são eventos naturais que ocorrem em todos os oceanos e podem estar associadas com a presença de toxinas que afetam a saúde humana. Neste trabalho monitorou-se a ocorrência de toxinas causadoras de PSP, DSP e ASP em moluscos cultivados no Ribeirão da llha em Florianópolis entre fevereiro e setembro de 2006. Amostras para identificação do fitoplancton e variáveis ambientais também foram coletadas. A temperatura da água variou entre 17 e $28 \stackrel{\circ}{\circ}$, a salinidade de 32 a $35 \%$ e a transparência da água de 0,6 a 3,1 metros, condições frequentemente observadas nesta área. A clorofila a variou de 1,1 a $5,9 \mathrm{mg} \mathrm{m}^{-3}$ caracterizando um ambiente mesotrofico. Os nutrientes dissolvidos não apresentaram valores anômalos, destacando as baixas concentrações de fosfato que indicam a pequena contribuição fluvial na região. Espécies nocivas observadas foram D. acuminata e D. caudata presentes nas amostras de rede de plâncton. $P$. minimum e o gênero Pseudo-nitzschia tiveram suas densidades máxima em $7,2 \times 10^{3}$ e $4,6 \times 10^{4}$ cél. $\mathrm{L}^{-1}$ respectivamente. Espécies não toxinas

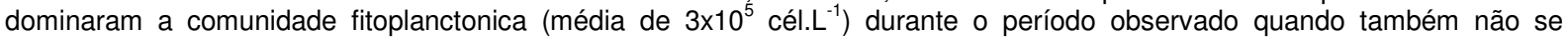
observaou a presença de toxinas nos tecidos dos moluscos.
\end{abstract}

PALAVRAS CHAVE: Monitoramento, Fitoplâncton, Maricultura

\section{Abstract: \\ Implementation and evaluation of monitoring of harmful algae and phycotoxins in a molluscs farm in Florianópolis - SC.}

Phytoplankton blooms are natural event and when it is associated with a harmful effect, they are called harmful algal bloom. Globally, the main syndromes caused by phycotoxins are PSP, DSP and ASP. This paper describes the results of the monitoring of the occurrence of harmful algae and phycotoxins at Ribeirão da llha, a mussel culturing area at Baia Sul/Florianópolis, southern Brazil, behind February and September of 2006. The occurrence of phycotoxins in Perna perna tissue was accessed by mouse bioassay and high performance liquid chromatography, while the presence of harmful species by light microscopy, from net and integral tube samples. The water temperature ranged form 17 to $28 \stackrel{\circ}{ } \mathrm{C}$, the salinity from 32 to $35 \%$ and the transparency from 0.6 to 3.1 meters. Chlorophyll a varied from 1.1 to $5.9 \mathrm{mg} \mathrm{m}^{-3}$, characterizing this as a mesotrophic environment. Harmful species observed included Dinophysis acuminata and $D$. caudata in plankton net samples and P. minimum and some species of Pseudonitzschia at low counting, with a maximum of $7.2 \times 10^{3}$ and $4.6 \times 10^{4}$ cél. $L^{-1}$,

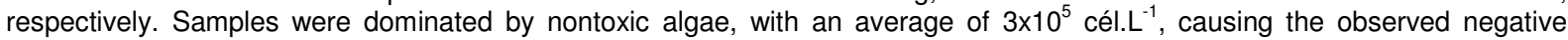
results for toxin analysis and bioassays.

KEY WORDS: Monitoring, Phytoplankton, Aquaculture.

\section{INTRODUÇÃO}

A maricultura envolve atividades de cultivo de moluscos em especial o de mexilhões, o de ostras e o de vieras. Em Santa Catarina a produção comercial de moluscos teve início no começo de 1990 e em 2005 representou $\pm 95 \%$ da produção nacional de moluscos de cultivo com 12.234 toneladas de mexilhões, 1.942 toneladas de ostras e 23.738 unidades de vieiras (Oliveira-Neto 2006).

Moluscos bivalves são organismos filtradores que se alimentam, entre outras coiasas, de organismos planctônicos e de matéria orgânica particulada. Poluentes, patógenos e/ou toxinas, podem acumular em seus tecidos e serem transferidos para níveis tróficos superiores causando intoxicações e danos a diversos grupos de organismos, inclusive o homem (Reguera 2002, Hallegraeff 2003). Embora sejam eventos naturais, florações de algas podem refletir condições adversas do ambiente. Espécies de algas tóxicas vêm sendo registradas no litoral sul do Brasil de longa data.

A maior parte das toxinas em ambientes costeiros marinhos é produzida, principalmente, por dinoflagelados e diatomáceas (Hallegraeff 2003). Entre os dinoflagelados destacam-se os gêneros Gymnodinium (Stein 1878), Alexandrium (Halim 1960), Dinophysis (Ehrenberg 1839), Pyrodinium (Plate 1906) e Prorocentrum (Ehrenberg 1833), responsáveis pela produção de toxinas neurológicas e gastrointestinais, causadoras da síndrome paralisante (PSP), da síndrome diarréica (DSP) entre outras (Balech 1998, Faust \& Gulledge 2002). Dentre das diatomáceas 0 gênero Pseudo-nitzschia (Peragallo 1897), possui espécies produtoras do ácido domoico, causador da síndrome amnésica (ASP) (Hasle \& Syverstsen 1997, Bates 1998, Lagos 2002).

Ocorrências de toxinas causadoras de PSP 
foram observadas em moluscos cultivados no Estado de Santa Catarina, porém sem intoxicação humana (Proença et al. 1999, Schramm et al. 2006). Toxinas diarréicas em moluscos são registradas desde 1990 (Proença et al. 1999a, Proença et al. 1999b, Proença \& Schmitt 2000) sendo que recentemente uma floração de Dinophysis acuminata (Claparède \& Lachmann 1859) no litoral de centro-norte de Santa Catarina, causou intoxicações em pelo menos 130 pessoas no litoral norte resultando na primeira proibição da colheita e comercialização de moluscos que se estendeu por um período de aproximadamente 21 dias (Proença et al. 2007). O primeiro registro do ácido domóico, causador da síndrome amnésica por consumo de moluscos (ASP), no Brasil ocorreu em 2001 em amostras de água de cultivos de moluscos da praia da Armação do Itapocoroy (município de Penha), associado à presença das ditomáceas Pseudo-nitszchia multisseries e da Pseudo-nitzschia australis (Proença \& Oliveira 1999; Villac et al. 2005; Mafra Jr. et al. 2006).
O presente trabalho apresenta os resultados do monitoramento de algas nocivas e de ficotoxinas em uma das principais regiões produtora de moluscos do Estado de Santa Catarina.

\section{MATERIAL E MÉTODOS}

A área de estudo abrange a região do distrito de Ribeirão da Ilha na Baía Sul, Ilha de Santa Catarina (Figura 1). A região é caracterizada como um estuário em forma de baía com águas abrigadas onde a profundidade média é de 6,0 metros e sua superfície de espelho d'água possui aproximadamente $215 \mathrm{~km}^{2}$, com dominância de circulação de marés sob influência de ventos do quadrante sul e nordeste. As entradas de água na Baía ocorrem através de uma conexão com a Baía Norte e outra com o mar ao sul. A região destaca-se pelas micro-bacias do rio Cubatão, rio Massiambú, rio Aririú, rio Ribeirão, além inúmeros pequenos córregos surgem ao longo da linha de costa em períodos de grande pluviosidade (Carvalho et al. 1998).

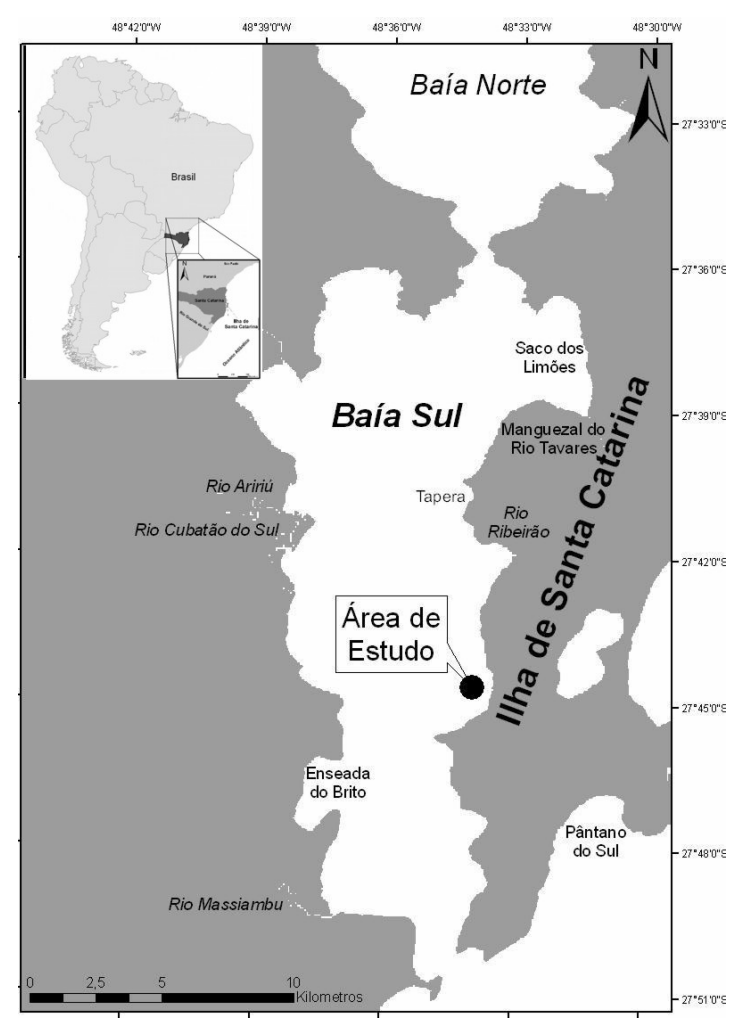

Figura 1 - Mapa da área de estudo com o ponto amostral (círculo preto) no Ribeirão da llha identificado.

Entre fevereiro e setembro de 2006 foram coletadas amostras quinzenais em um ponto na área mais exposta do cultivo. As variáveis, temperatura, salinidade e transparência da água, foram determinadas in situ, com a utilização de um multianalisador YSI-30/10 e um disco de secchi $(20$ 
$\mathrm{cm}$ de diâmetro). As amostras de água para análises químicas e microscópicas foram tomadas de forma integral na coluna d'água por meio de uma mangueira de plástico com $30 \mathrm{~mm}$ de diâmetro e 3 metros de comprimento dotada de um registro em uma das extremidades para se evitar a perda de água. Parte da amostra $(200 \mathrm{~mL})$ foi filtrada em um filtro de fibra de vidro, do tipo GF 50-A Schleicher \& Schuell (poro de $0,6 \mathrm{~mm}$ ), visando às análises de clorofila $a(\mathrm{chl} a)$ e nutrientes inorgânicos dissolvidos. Outra parte da amostra integral $(200 \mathrm{~mL})$ foi fixada com lugol $1 \% \mathrm{e}$ destinada à contagem das algas. Com uma rede de plâncton (abertura de malha de $20 \mu \mathrm{m}$ ), arrastada obliquamente por 2 minutos, coletou-se as amostras qualitativa das algas, onde uma parte da amostra foi fixadas com formol $4 \%$ e a outra parte foi mantida viva.

Para a análise de clorofila, foi realizado um extrato acetônico (acetona P.A. 99,5\%), sonicado com sonda Sonics ${ }^{\circledR}$ por aproximadamente 30 segundos. Uma alíquota de $160 \mu \mathrm{L}$ do extrato foi misturada com $40 \mu \mathrm{L}$ de acetato de amônio, homogeneizado e imediatamente injetado no sistema de cromatografia líquida de alta eficiência (HPLC), configurado com uma coluna cromatográfica Pecosphere C-18 33X4 $(3 \mu \mathrm{m})$ e uma fase móvel composta por metanol e acetona grau HPLC (8:2), em um fluxo de $0,8 \mathrm{~mL} \cdot \mathrm{min}^{-1}$. A detecção ocorreu em um fluorímetro Shimadzu RF551 no comprimento de onda de $430 \mathrm{~nm}$ de excitação e $668 \mathrm{~nm}$ de emissão, segundo a metodologia descrita por (Mantoura et al. 1997) adaptado por (Proença 2002). A calibração se deu através da injeção de quantidades conhecidas de solução padrão de chl a pura (Sigma).

As análises dos nutrientes inorgânicos dissolvidos foram realizadas no Laboratório de Oceanografia Química da UNIVALI, como seguem: fosfato $\left(\mathrm{P}^{-} \mathrm{PO}_{4}{ }^{3-}\right)$, silício $\left(\mathrm{Si}-\mathrm{SiO}_{2}{ }^{-}\right)$, nitrito $\left(\mathrm{N}-\mathrm{NO}_{2}{ }^{-}\right)$, nitrato $\left(\mathrm{N}-\mathrm{NO}_{3}{ }^{-}\right)$e amônio $\left(\mathrm{N}^{-} \mathrm{NH}_{4}{ }^{+}\right)$, através do método colorimétrico clássico adaptado de Strickland \& Parsons (1972).

A identificação das algas ocorreu à partir das amostras vivas e a quantificação ocorreu nas amostras integrais através da técnica de Ütermohl (1958), com o auxílio de um microscópio ótico invertido modelo Olympus ${ }^{\circledR}$ IX50 nos aumentos de $200 x$ ou $400 x$.

Os ensaios e análises das toxinas foram realizados com a espécie de mexilhão (Perna perna), a partir de dois extratos, um hidrossolúvel (para toxinas paralisantes e amnésica) e outro lipossolúvel (para toxinas diarréicas). Os ensaios para toxinas paralisantes e diarréicas foram realizados com camundongos, tipo suíço, registrando-se os tempos de morte entre um prazo de 60 min e 24 horas, de acordo com a metodologia descrita pela AOAC № 959.08 (2000) e por Yasumoto et al. (1984). Para as toxinas amnésicas 0 extrato hidrossolúvel foi purificado por centrifugação e injetado no sistema de cromatografia líquida de alta eficiência (HPLC) de acordo com o método de Quillian et al. (1995). A calibração se deu através da elaboração de uma curva com repetidas injeções de volumes conhecidos de solução padrão de ácido domóico.

\section{RESULTADOS}

A temperatura variou 9,5 graus ao longo do período observado, tendo seus extremos, em 17,5 ำ e $28 \stackrel{\circ}{\circ}$. A salinidade esteve sempre acima de $32 \%$ atingindo máximo de $35 \%$ (Figura 2 A-B). A transparência da água apresentou um valor médio de 1,7 oscilando entre 1,0 a 3 metros e a concentração de chl a variou de 1,0 a 4,5 $\mu \mathrm{g} . \mathrm{L}^{-1}$ com média de 2,9 $\mu g . L^{-1}$ (Figura 2 C-D). 

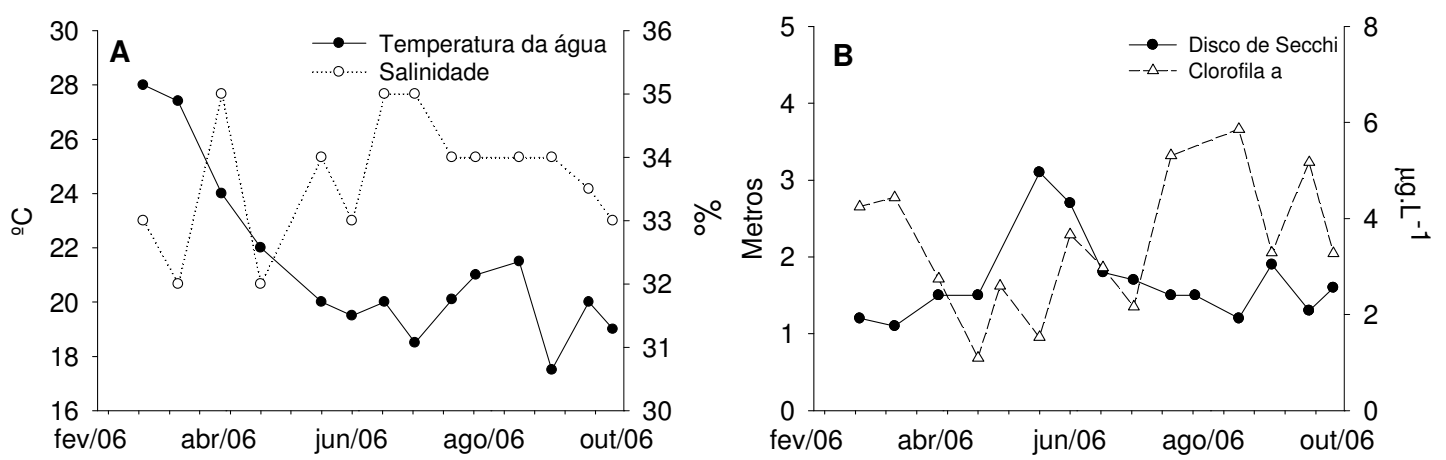

Figura 2 - A) Temperatura da água $\left({ }^{\circ} \mathrm{C}\right)$ e clorofila a $\left(\mu \mathrm{g} \cdot \mathrm{L}^{-1}\right)$, B) salinidade (\%o) e transparência da água (profundidade do disco de Secchi em metros) ao longo do período no Ribeirão da llha.

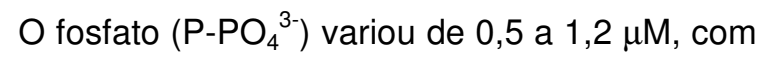
média de $0,74 \mu \mathrm{M}$. $O$ nitrogênio inorgânico nas formas, nitrato e nitrito $\left(\mathrm{N}-\mathrm{NO}_{3}^{-}\right.$e $\left.\mathrm{N}-\mathrm{NO}_{2}^{-}\right)$variaram entre 0,27 e 0,25 para os valores mínimos e 0,51 e 2,58 para os valores máximos, tendo como valores médios, 0,98 e $0,34 \mu \mathrm{M}$ respectivamente. Os valores de concentração do nitrogênio na forma do íon amônio $\left(\mathrm{N}^{-\mathrm{NH}_{4}}{ }^{+}\right)$, variaram de 3,97 e 14,17 $\mu \mathrm{M}$, sendo o valor médio de $8,01 \mu \mathrm{M}$ e o silício $\left(\mathrm{Si}-\mathrm{SiO}_{2}{ }^{-}\right)$ variou de 2,70 e $32,55 \mu \mathrm{M}$ com média de $15,41 \mu \mathrm{M}$ (Figura 3).
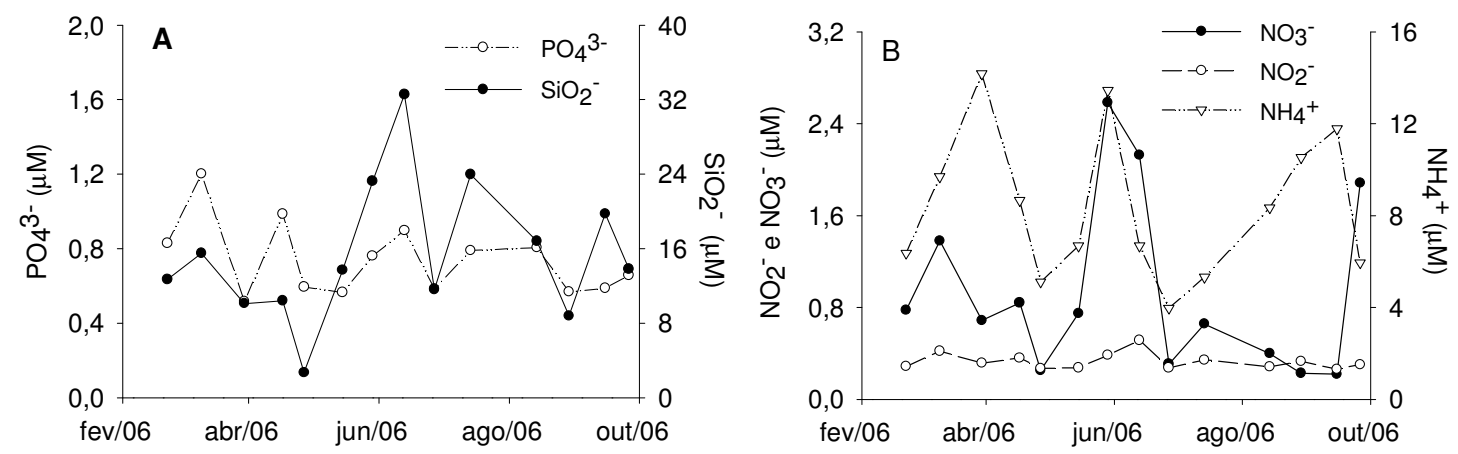

Figura 3 - A) $\mathrm{P}_{-} \mathrm{PO}_{4}{ }^{3-}$ e $\mathrm{Si}-\mathrm{SiO}_{2}{ }^{-}$em $\mu \mathrm{mol} . \mathrm{I}^{-1}$, B) $\mathrm{N}-\mathrm{NO}_{3}{ }^{-}$e $\mathrm{N}-\mathrm{NO}_{2}{ }^{-}$e N-NH${ }_{4}^{+}$em $\mu \mathrm{mol} . \mathrm{L}^{-1}$ ao longo do período no Ribeirão da llha.

As análises de microscopia identificaram 13 espécies de algas nocivas distribuídas em 5 gêneros (Alexandrium, Dinophysis, Prorocentrum, Pseudonitzschia e Chatonella). Entre os dinoflagelados, as espécies Dinophysis acuminata, Dinophysis rotundata (Claparède \& Lachmann 1859), estavam presentes apenas nas amostras de rede. O dinoflagelado Prorocentrum minimum (Schiller 1933) foi classificadas como nocivo, porém não causador de DSP.

Entre as diatomáceas, quatro espécies do gênero Pseudo-nitzschia spp., sub-classificadas em duas espécies do complexo Nitzschia seriata (Hasle 1971) e duas do complexo Nitzschia delicatíssima (Hasle 1971) foram identificadas como potencialmente tóxicas. A porcentagem de ocorrência de Pseudo-nitzschia spp. no período foi superior a $94 \%$, e sua maior densidade, relativa ao total de outras espécies, foi de 20,20\%. Na Figura 4 são apresentadas as densidades dos gêneros Pseudonitzschia e Prorocentrum além da densidade total de outras espécies registradas em cada amostra. 


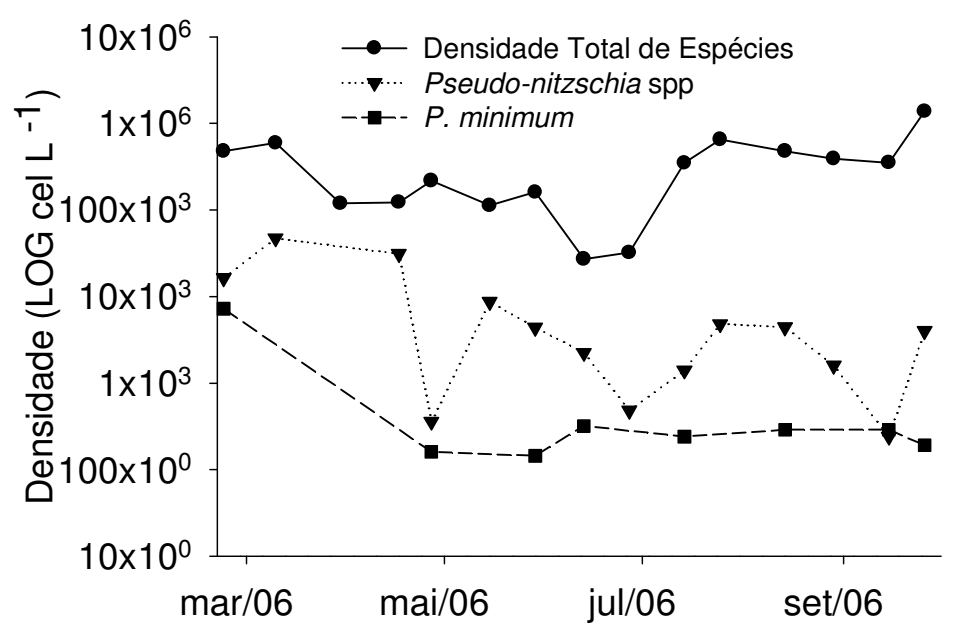

Figura 4 - Estimativas das densidades celulares das algas Pseudo-nitzschia spp, Prorocentrum spp, e da densidade total de outras espécies observadas ao longo do período monitorado no distrito do Ribeirão da llha.

Os ensaios das toxinas causadoras de PSP e DSP, não apresentaram níveis de toxinas detectáveis por este tipo de método, entretanto não se garante a isenção destas toxinas nos tecidos dos moluscos. As análises cromatográficas para toxinas causadoras de ASP não detectaram a presença do ácido domoico em nenhuma das amostras.

A análise de componentes principais expressou
$57,35 \%$ da variação dos resultados (Figura 5). Três agrupamentos, um com as variáveis salinidade e transparência da água, um com a temperatura da água com o nitrogênio e a sílica e outro entre o fosfato, a chl a e a densidade de $P$. minimum e Pseudo-nitzschia spp., relacionaram-se de forma direta no eixo $1(37,48 \%)$ e inversa no eixo 2 $(19,87 \%)$.

análise de Componentes Principais (55,10\%)

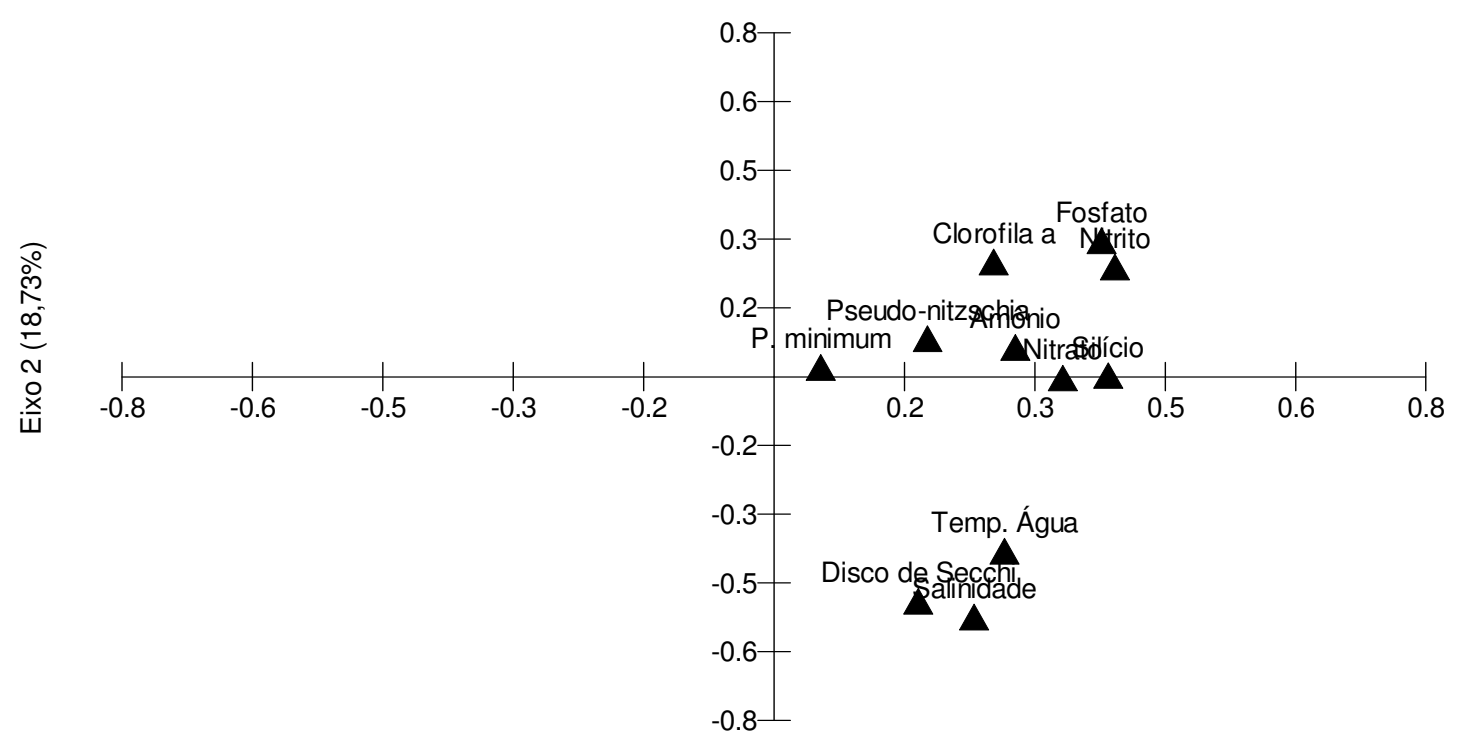

Eixo $1(36,35 \%)$

Figura 5 - Análise de Componentes Principais, o eixo 1 representando $36,35 \%$ dos resultados e o eixo 2 representado $18,73 \%$, totalizando $55,10 \%$ das variações dos resultados. 


\section{DISCUSSÃO}

A temperatura da água apresentou um comportamento típico para o litoral de Santa Catarina, com valores maiores no verão e valores menores no inverno (Carvalho et al. 1998). A salinidade demonstrou que 0 aporte de água doce nesta região apresenta-se pouco significativo, diferindo de outras enseadas, como a Armação do Itapocoroy e a baía de Zimbros, que registram baixas salinidades devido a influência de grandes rios como o Rio Itajaí Açu e o Rio Tijucas (Schettini et al. 1999, Proença 2002, Mafra Jr. et al. 2006).

A transparência da água determinada através da profundidade de medida do disco de secchi demonstrou que a zona eufótica estende-se até o fundo devido a baixa profundidade local, podendo ocorrer limitação de luz nas camadas mais próximas ao fundo em determinadas situações.

A variação da chl a ao longo do período observado foi similar a outras regiões do litoral catarinense e do sul do Brasil (Proença 2002, Mafra Jr. et al. 2006). Na transição do verão para o inverno ocorreu uma diminuição da chl a provavelmente associada à mudanças no comportamento das massas d'água adjacentes.

As baixas concentrações de fosfato ao longo do período possivelmente refletiram a pouca contribuição de águas epicontinentais nesta região. As elevadas quantidades de sílica, principalmente no início do inverno, possivelmente estão refletindo a presença de massas d'água provenientes da plataforma continental do sul que neste período ganham força e deslocam-se para o norte. $O$ nitrogênio nas três formas iônicas monitoradas apresentou um comportamento correlato com as condições que promovem a ocorrência da sílica.

A abundância dos dinoflagelados nas amostras foi relativamente baixa (média de $1 \%$ do total de classes), sendo as diatomáceas 0 grupo de organismos que dominaram a comunidade planctônica ao longo do período observado. Internacionalmente relaciona a presença de toxinas

\section{AGRADECIMENTOS}

Agradecemos à empresa Fazenda Marinha Atlântico Sul, causadoras de ASP com dominâncias superiores a 50\% de Pseudo-nitschia spp. no plâncton (Bates 1998, Hallegraeff 2003). A ausência de toxinas correlacionou-se com a ausência ou baixa dominância das espécies nocivas e potencialmente tóxicas na comunidade fitoplanctônica, possivelmente refletindo uma condição de estabilidade ecológica do ambiente em questão.

$\mathrm{Na}$ análise multi-variada, a salinidade fortemente associada a transparência da água e contraposta à presença de fosfato possivelmente reflete que a presença de água marinha domine esta região. O agrupamento da chl $a$, da densidade de algas e do fosfato induz que a influência continental pode favorecer a produção primária nesta área.

Provavelmente as marés estejam atuando como a principal força responsável pela circulação, dinâmica de nutrientes e pelo controle da produção primária, próximo a área de cultivo. A entrada de água doce em períodos chuvosos através do escoamento superficial a ação dos ventos na formação das células de circulação e nos processos de deposição seca podem promover alterações em micro-escala nas características da água próximo ao cultivo. A presença de ambientes adjacentes ao cultivo como o Saco dos Limões e o manguezal do rio Tavares podem estar atuando de forma sinérgica contribuindo com matéria orgânica e de compostos dissolvidos.

Embora não se tenha registrado a presença de toxinas nos moluscos durante o período pesquisado (2006), a ocorrência de espécies tóxicas, próxima a área de cultivo, torna o monitoramento necessário para a prevenção e o controle, pois existe a possibilidades de ocorrerem florações de algas nocivas com a produção de toxinas DSP e ASP próximo ao cultivo, hipótese confirmada no ano de 2007 quando a salinidade foi anormalmente mais baixa que a média histórica mesmo em um período de baixa pluviosidade, com possibilidades de reincidência, nesta região e em outras localidades do litoral de Santa Catarina (Proença et al. 2007).

por toda cooperação e atenção para a realização deste trabalho. À Pró-Reitoria de Pesquisa, Extensão e Cultura da UNIVALI à Dra . Kátia N. Kuroshima do Lab. Química e ao Dr. Marcel Frajblat diretor do Biotério da UNIVALI. 


\section{BIBLIOGRAFIA}

AOAC. 2000. Paralytic Shellfish Poisoing. Official Methods 959.08. Association of Official Analytica Chemists. USA. Arlington. p 59-61.

BALECH, E. 1998. Los Dinoflagelados del Atlántico Sudoccidental. Instituto Español de Oceanografia, Madrid.

BATES, SS. 1998. Ecophysiology and Metabolism of ASP Toxins Production. In: Hallegraeff, GM, DM Anderson \& AD Cembella (ed.) Physiological Ecology of Harmful Algal Blooms. Springer. p 267-293.

CARVALHO, JLB, CAF SCHETTINI \& TM RIBAS. 1998. Estrutura Termohalina do Litoral Centro-Norte Catarinense. Notas Técnicas da Facimar. 2. p 181-197.

FAUST, MA \& RA GULLEDGE 2002. Identifynig Harmful Marine Dinoflagellates. National Museu of Natural History. Washington, DC.

HALLEGRAEFF, GM. 2003. Harmful Algal Bloom: a global overview. In: HALLEGRAEFF, GM, DM ANDERSON \& AD CEMBELLA (ed.) Manual on Harmful Marine Microalgae. UNESCO. Chap. 1: 25-50.

HASLE GR \& EE SYVERSTSEN. 1997. Marine diatoms. In: THOMAS C. R. (ed.). Identifying Marine Phytoplankton. Academic Press, New York, Chap. 2: 5-386.

Lagos, N. 2002. Principales toxinas de origen fitoplanctónico: identificación y cuantificación mediante cromatografía líquida de alta resolución (HPLC) In: Sar, E. A.; B, Reguera \& ME, Ferrario. Floraciones Algales Nocivas en el Cono Sur Americano. UNESCO. p 55-76.

MAFRA JR., LL, LF FERNANDES \& LAO PROENÇA 2006. Harmful Algae and Toxins in Paranaguá Bay, Brazil: Bases for Monitoring. Brazilian Journal of Oceanography. 54. p 107-121

MANTOURA, FA, SW JEFFREY, CA LLEWELLYN, H CLAUSTER \& CE MORALES. 1997. Comparison between spectrophotometric, fluorometric and HPLC methods for chlorophyll analysis. In: JERFFREY, SW, RFC MANTOURA \& SW WRIGHT. (ed.) Phytoplankton Pigments in Oceanography. UNESCO, PARIS. p. 361-380.

OLIVEIRA-NETO FM. Síntese informativa da produção de moluscos (mexilhões, ostras e vieiras) no estado de Santa Catarina. Disponível em: http://www.epagri.rct-sc.br/. Acesso 10/12/2006.

PROENÇA, LAO, $N$ LAGOS, L RÖRIG, M SILVA \& $S$ GUIMARÃES. 1999. Occurrence of paralytic shellfish toxins PST in southern Brazilian waters. Ciência e Cultura - Journal of the Brazilian Association for the Advancement of Science. 51: $p$ 16-21.

PROENÇA, LAO \& GF OLIVEIRA. 1999. Análise de ácido domóico em moluscos cultivados no litoral de Santa Catarina. Notas Técnicas da Facimar, 3: p 27-32.
PROENÇA, LAO, F SCHIMITT, SP GUIMARÃES \& LR RÖRIG. 1999a. Análise de toxinas diarréicas em duas espécies e Prorocentrum (Dinophyceae) isoladas em área de cultivo de moluscos. Notas Técnicas da Facimar, 3: p 41-45.

PROENÇA, LAO, F SCHIMITT, MS TAMANAHA, S GUIMARÃES \& L RÖRIG. 1999b. Produção de ácido okadaico, uma toxina diarréica, por Dinophysis acuminata em Santa Catarina. Atlântica, 21: p 121-127.

PROENÇA, LAO \& F SCHIMITT. 2000. Ocorrência do Dinoflagelado do Gênero Dinophysis (ENRENBERG, 1893) na Enseada de Cabeçudas (Verão e Outono de 1999). Notas Técnicas da Facimar. p 41-45.

PROENÇA, LAO. 2002. Clorofila a do Fitoplâncton em Seis Enseadas Utilizadas para o Cultivo de Moluscos Bivalves no Litoral de Santa Catarina. Notas Técnicas Facimar. 6: p 33-34.

PROENÇA, LAO, MA SCHRAMM, MS TAMANAHA \& TP ALVES. 2007. Diarrhoetic Shellfish Poisoing (DSP) Outbreak in Subtropical Southwest Atlantic. Harmful Algae News. UNESCO. 33: $p$ 19-20.

QUILLIM, MA, M XIE \& WR HARDSTAFF. 1995. Rapid extraction and cleanup for liquid chromatographic determination of domoic acid in unsalted sea food. Jornal of AOAC International. 78: $p$ 543-554.

REGUERA, B. 2002. Establecimiento de um Programa de Seguimiento de Microalgas Tóxicas. In: SAR, EA, B REGUERA \& ME FERRARIO. (eds.) Floraciones Algales Nocivas em el Cono Sur Americano. UNESCO. p 19-55.

SCHRAMM, MA, MS TAMANAHA, LH BEIRÃO \& LAO PROENÇA. 2006. Toxinas paralisantes em mexilhões Perna perna em áreas de cultivo da costa sul do Brasil: estudo de caso. Alimentos e Nutrição, Araraquara, v.17

SCHETTINI, CAF, JLB CARVALHO \& EC TRUCCOLO. 1999. Aspectos Hidrodinâmicos da Enseada da Armação de Itapocoroy, SC. Notas Técnicas da Facimar. 3. p 99-109.

STRICKLAND, JD \& TR PARSONS. 1972. A Pratical Handbook of Seawater Analysis. Fisheries research. Board of Canada Bulletin. 2.

UTERMÖHL, H. 1958. Zur Vervollkommung der Quantitativen Phytoplankton Methodik. Mitt. Int. Ver. Limnol. 9. p 1-38.

VILLAC, MC, S MELO, M MENEZES, DR TENENBAUM. 2005. Pseudo-Nitzschia brasiliana (Bacillariophyceae), an Opportunistic Diatom on the Coast of the State of Rio de Janeiro, Brazil. Atlântica, Rio Grande, 27(2): 139-145.

YASUMOTO, T, ML FERNANDÉZ, A MÍGUEZ, E CACHO, A MARTINEZ \& A DIOGÉNE. 2002. Bioensayo com mamíferos y Ensaios Bioquímicos y Celulares para la Detección de Focitoxinas. In: SAR, EA, B REGUERA \& ME FERRARIO. (eds.) Floraciones Algales Nocivas em el Cono Sur Americano. UNESCO. $p$ 79-112.

Recebido: 29/09/2008

Aceito: 10/10/2009 
